\title{
Mycobacterium tuberculosis: a continuing cause of sudden and unexpected death in west London
}

\author{
R C Chapman, S M Claydon
}

\begin{abstract}
Aims: To describe the pathological and background features of several cases of tuberculosis diagnosed at post mortem examinations and performed on behalf of HM Coroner over a three year period in west London.

Methods: Postmortem examinations were carried out by two pathologists working at hospital and public mortuaries in west London. Cases of tuberculosis were provisionally diagnosed on gross examination and the diagnosis confirmed on haematoxylin and eosin and Ziehl-Neelsen staining of retained tissues. The background information was obtained by scrutinising hospital records and by direct enquiry to general practitioners by coroners' officers.
\end{abstract}

Results: Thirteen cases of pulmonary tuberculosis were diagnosed during the period. No other cause of death was found. The incidence of fatal pulmonary tuberculosis was $\mathbf{0} \cdot \mathbf{2 8} \%$ of coroners' necropsies in the study region. Cases had been referred to the coroner because death had occurred unexpectedly, or because no recent medical attention had been sought. Most cases arose among the elderly Asian immigrant population or the homeless or the alcoholic, or both. In 10 cases the macroscopic findings strongly indicated pulmonary tuberculosis and in the other three the diagnosis was considered to be a differential diagnosis.

Conclusions: These findings have important health implications for those carrying out post mortem examinations from these groups as well as for those involved with the continuing care of immigrant or vagrant populations.

\section{Methods}

We examined the 13 cases while working at Ealing Hospital, Charing Cross Hospital, and Fulham public mortuaries between September 1987 and August 1990. The total number of coroners' necropsies in those mortuaries over that period was 4600 , this being about one third of the total number of deaths in that area over that period. The geographical area covered was most of north west London and Middlesex (figure).

Routine necropsies were performed. There was a history of tuberculosis in only four cases and these lungs were placed in formalin immediately after careful evisceration. The other nine cases were eviscerated by unsuspecting mortuary technicians and the lungs were subsequently opened by pathologists, tuberculosis being diagnosed after disection and examination of the internal macroscopic appearances of the lung tissue. In 10 cases these appearances strongly indicated active pulmonary tuberculosis and in the other three they suggested tuberculosis as a differential diagnosis. Lung sections in each case were stained with haematoxylin and eosin and Ziehl-Neelsen stains.

\section{Results}

Over three years the 13 cases gave an incidence of tuberculosis among the coroners' necropsies for the area of $0.28 \%$. Details of the 13 cases are listed in table 1 . Six were from the Indian subcontinent; six were indigenous caucasians; one was Afro-Caribbean.

Of the six Indians, all were elderly first generation immigrants living with large families. The three men had all received recent medical treatment for non-related conditions; the three women had received no medical treatment and had never visited their family doctors, who indeed had no information about them on file.

Of the six caucasians, three were semivagrant alcoholic men, two were elderly men living alone and known to drink and smoke heavily. The last was an elderly woman who lived a hermit-like existence. She had no known family or friends.

The black man was the only case under 50 years of age. He was schizophrenic and had lived in various hostels. His medical follow up was erratic due to frequent non-attendance at outpatient clinics.

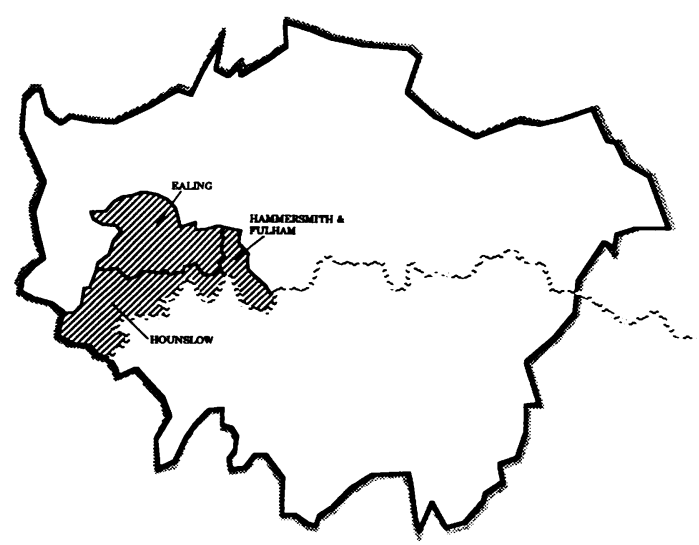

Three London boroughs in which the 13 deaths occurred. 
Table 1 Social, racial and medical characteristics

\begin{tabular}{|c|c|c|c|c|}
\hline Case No & Age & $\operatorname{Sex}$ & Ethnic origin & Other factors \\
\hline 1 & 59 & $\mathbf{M}$ & White & $\begin{array}{l}\text { Alcoholic, hostel dweller. Known TB in } \\
\text { past. }\end{array}$ \\
\hline 2 & 50 & $\mathbf{M}$ & White & Alcoholic, squatter/semi-vagrant. \\
\hline 3 & 52 & $\mathrm{~F}$ & Indian subcontinent & $\begin{array}{l}\text { First generation immigrant, living with large } \\
\text { family. }\end{array}$ \\
\hline 4 & 76 & $\mathbf{F}$ & White & Recluse, living alone. \\
\hline 5 & 64 & $\mathbf{M}$ & White & $\begin{array}{l}\text { Recluse, living alone. Died } 2 \text { days after } \\
\text { hospital admission. Sputum positive for } \\
\text { AAFB. Heavy drinker and smoker. }\end{array}$ \\
\hline 6 & 50 & M & White & Alcoholic, vagrant, one leg amputated. \\
\hline 7 & 46 & $\mathbf{M}$ & Afro-Caribbean & Schizophrenic. Sometime hostel dweller. \\
\hline 8 & 75 & $\mathbf{M}$ & Indian subcontinent & $\begin{array}{l}\text { First generation immigrant. Cerebrovascular } \\
\text { accident } 1987 \text {. Suspected of having TB and } \\
\text { receiving treatment. }\end{array}$ \\
\hline 9 & 76 & $\mathrm{~F}$ & Indian subcontinent & $\begin{array}{l}\text { First generation immigrant living with large } \\
\text { family. }\end{array}$ \\
\hline 10 & 75 & $\mathbf{M}$ & Indian subcontinent & $\begin{array}{l}\text { First generation immigrant. Transurethral } \\
\text { resection of prostate } 1987 \text {. Tuberculous } \\
\text { meningitis diagnosed } 3 \text { weeks previously. }\end{array}$ \\
\hline 11 & 67 & $\mathbf{M}$ & Indian subcontinent & $\begin{array}{l}\text { First generation immigrant. Coronary artery } \\
\text { bypass } 1987 \text {. }\end{array}$ \\
\hline 12 & 84 & $\mathbf{F}$ & Indian subcontinent & $\begin{array}{l}\text { First generation immigrant living with large } \\
\text { family. }\end{array}$ \\
\hline 13 & 60 & $\mathbf{M}$ & White & $\begin{array}{l}\text { Heavy smoker and drinker. Lived alone. } \\
\text { Chronic obstructive airways disease. }\end{array}$ \\
\hline
\end{tabular}

Four of the patients died in hospital, the rest died at home, or in hostels or squats. In six cases death occurred at the end of a period of known ill health. In the remaining cases there was no history of precipitating illness. In most of these cases death seemed to have occurred within 24 hours of their last appearing well or of their condition causing concern.

The macroscopic findings are detailed in table 2 .

The microscopic findings showed classic features of pulmonary tuberculosis in each of

Table 2 Macroscopic findings of 13 cases of tuberculosis

Case 1: Fibrinopurulent pericarditis (tuberculous on Ziehl-Neelson staining). Scarred, blackened lungs with inflamed respiratory mucosa and diffuse necrotic cavities of varied size containing caseous material. Caseous material also seen in hilar nodes.

Case 2: Respiratory mucosa inflamed and airways full of yellow pus. The lungs contained caseous material lying in small peripheral nodules most abundant in the apices of both upper lobes. The lower lobes were consolidated with microabscesses and pus in both upper lobes. The lower lobes were consolidated with microabscesses and
small bronchi. The lungs were heavy and softened, with pleural adhesions.

Case 3: Inflamed respiratory mucosa. Lungs green in colour and softened. Both upper lobes contained necrotic yellowish cavities, some containing caseating material and some pus. Both apices were adherent to the chest wall.

Case 4: Inflamed respiratory mucosa. Lungs were green in colour and softened. Large necrotic cavity in left upper lobe with numerous small yellow abscess cavities around this. No adhesions.

Case 5: Inflamed respiratory mucosa. Left upper lobe contained a large caseating cavity at its apex. Smaller necrotic areas seen in the left upper and right lower lobes. Lung parenchyma was tough and black; little normal lung seen. Pronounced adhesions. Prominent pulmonary arteries present.

Case 6: Chronic bronchitis and emphysema, oedema, congestion and severe adhesions. Necrotic cavity right apex with surrounding consolidating pneumonia.

Case 7: Mild inflammation of trachea and large bronchi. Lungs dark and congested. All small bronchi inflamed and filled with tenuous white mucus. Yellow necrotic lesions seen in both upper lobes. Pronounced pleural adhesions.

Case 8: Large airways healthy. Lungs softened, oedematous and congested with patchy consolidation, purulent pleurisy and pronounced adhesions around the right lowe lobe. Multiple tiny pale nodules in the small and large intestines (histology confirmed intestinal tuberculosis).

Case 9: Mild inflammation of upper airways. Severe inflammation of lower airways. Lung collapsed with emphysema. Left upper lobe grossly adherent to chest wall and contained caseating yellow cavities.

Case 10: Diffuse inflammation of airways. Lungs dark, well expanded and congested with yellow pus occluding all small bronchi. Some patches of consolidation. Some caseating areas in both upper lobes.

Case 11: Upper airways healthy. Both lower lobes showed pneumonic consolidation with pus in small bronchi. A mass of firm white tissue $3 \mathrm{~cm}$ wide lay in the right upper lobe. This was considered to be a tumour before microscopic examination.

Case 12: Inflamed trachea and bronchi. Right upper lobe stuck to chest wall and contained multiple small caseating cavities with pale greyish surrounding parenchyma. Pneumonic consolidation involved all other lung lobes. Bilateral cloudy pleural effusions.

Case 13: Trachea and major bronchi inflamed and full of thick yellow pus. Bronchial tree thickened. Diffuse emphysema. Adhesions of both lungs to chest wall. Left upper lobe contained multiple small solid yellow cavities each about $0.5 \mathrm{~cm}$ wide. The right upper and middle lobes contained areas of firm white tissue with surrounding consolidation and pleurisy. Diffuse pneumonic change seen. The lesions in the right lung were initially considered malignant but all lesions were found to be tuberculous. the 13 cases. Ziehl-Neelsen staining showed acid-alcohol fast bacilli in all but case 8 .

\section{Discussion}

The finding of an incidence of tuberculosis of $0.28 \%$ in coroners' post mortem examinations is similar to that of Whittington in Birmingham (1977-81), who described an incidence of $0.3 \%$. ${ }^{1}$ These 13 deaths were referred to the coroner because death was sudden and unexpected. The cause was not expected to be pulmonary tuberculosis even in the recently diagnosed cases. In each case no one was aware of the severity of the underlying pathology.

Kantor et al described nosocomial transmission of tuberculosis from unsuspected disease, with nine out of 56 hospital staff (16\%) developing pulmonary tuberculosis, from a patient with undetected generalised tuberculosis. $^{2}$ Only three out of $333(0.9 \%)$ of staff not exposed to this patient but otherwise of similar risk developed tuberculosis ( $p<0.0001$ ). Lundgren et al described the infection in three medical students and one technician after exposure to a case of pulmonary tuberculosis discovered for the first time at necropsy. ${ }^{3}$

The pathological findings indicate that the fatal pathology in each case was tuberculous pneumonia. In six cases this clearly arose as a result of well documented chronic ill health, and the disease had been successfully diagnosed in four. In the remainder, however, there was no history of preceding illness because of the vagrant or hermit-like existence of the deceased. In most of these death ocurred within 24 hours of their last appearing well. In three elderly Asians (cases 3, 9, and 11) with well documented histories, death occurred due to sudden collapse and within 12 hours of their condition causing concern to relatives. In case 13 death occurred within hours of appearing well to a number of witnesses in the street.

Our findings highlight two groups who are particularly at risk of dying from pulmonary tuberculosis even in an environment where adequate care is available: elderly Asian immigrants and older vagrant or alcoholic men.

Preventive methods require that these groups regularly attend medical check ups but compliance is unlikely for varying reasons. This lack of compliance gives the disease opportunity to attack not only the individuals concerned but also those living with them and those in the post mortem room who attend the subsequent necropsy. It is therefore important that those caring for the groups at risk and those involved with post mortem work are aware of the possibility of active pulmonary tuberculosis in these people even though the incidence is low.

The pathological findings in the 13 cases described in this report were all typical for cases of active pulmonary tuberculosis. However, Anderson et al have shown that the accuracy of clinical diagnosis of pulmonary tuberculosis has declined over the past 50 years. ${ }^{4}$ Katz et al described 82 cases of active tuberculosis in inpatients only diagnosed at 
necropsy over a 21 year period (1960-1980). ${ }^{5}$ Seventy five per cent of these patients were over 50 years of age and many were immunosuppressed due to disease or drugs. ${ }^{5}$ Diagnostic measures for tuberculosis were not performed in $25 \%$ of these cases. In those investigated skin tests were negative in $75 \%$ and the others were borderline cases in whom the diagnosis of tuberculosis could not be confirmed.

Robbins et al comment on the incidence of tuberculosis, stating that although now treatable and preventable, it is still the single most important bacterial infection worldwide. ${ }^{6}$ Its true incidence cannot be determined because:

(1) Only a fraction of persons with $M$ tuberculosis manifest clinical disease at any one time; (2) all infected persons remain indefinitely at risk of developing active disease; (3) case reporting is always incomplete.

In 1974 the WHO estimated 7 million cases of active disease with great worldwide variety and stated "tuberculosis flourishes wherever there is poverty, malnourishment, and lack of adequate medical care ... no racial or economic group has proved resistant to sustained exposure, although susceptibility clearly differs among individuals."?

Citron described the epidemiology of tuberculosis, stating that it was on the increase in developing countries as their population had doubled in the past three decades and control measures were inadequate. ${ }^{8} \mathrm{He}$ estimated that at least 10 million people worldwide developed tuberculosis each year and that at least 3 million died of it, mainly in developing countries. Citron's report showed that in Britain tuberculosis was now relatively rare in the young, and he identified two high risk groups: (1) elderly white men, the main source of infection in this country; (2) immigrants from Asia and other countries of high prevalence.

The Medical Research Council Tuberculosis and Chest Diseases Unit estimated the annual notification rates for London in 1983 as follows: per 100000 population: $13 \cdot 1$ (16.3 in 1979) for indigenous caucasians and 204 (353 in 1979) for those from the Indian subcontinent. ${ }^{9} 10$

The report found that Indians born in the United Kingdom had a much lower incidence of infection than those born abroad and that recent immigrants had the highest incidence of all. In their opinion the high tuberculous Indian:white ratio is due to overcrowding and poorer housing, and the association between high incidence and poor socioeconomic conditions is a major factor in explaining the differences in the incidence of tuberculosis (per 100000 caucasian population) which ranged from $37 \cdot 0$ in Tower Hamlets to $4 \cdot 1$ in Bromley.

Other authors have confirmed the increased incidence of tuberculosis in alcoholics, vagrants, hostel dwellers, and in those who are mentally ill. Capewell et al described a high prevalence of the disease in male hostel dwellers over 50 years old. ${ }^{10}$ They noted poor treatment compliance and poor attendance at follow up. Ramsden et al noted an increased incidence of tuberculosis in alcohol misusing homeless men than in non-alcohol-misusing homeless and also noticed problems of compliance with long term treatment. ${ }^{11}$ In the USA McAdam et al stated that $4.3 \%$ of hostel dwellers have active tuberculosis. ${ }^{12}$ Ohta et al showed that the incidence of tuberculosis was significantly higher than that of the general population for both male and female schizophrenic patients. $^{13}$

Other predisposing factors include diabetes and partial gastrectomy, with Chanarin and Stephenson describing the higher incidence of tuberculosis in strict vegetarians, noting dietary deficiencies of iron and cobalamin in these individuals. $^{14}$

The incidence of tuberculosis will continue to decline but large groups of third world immigrants will present problems, especially if from areas where there is a high incidence of primary drug resistant strains. ${ }^{15}$ Middle aged to elderly men also have an increased incidence. It would be premature to abandon Bacille bilié de Calmette-Guérin immunisation: "in some areas the disease has become so uncommon that the skills of prevention, diagnosis, treatment and control may no longer be adequate ... the fact that there is a significant continuing mortality from what should be an eminently treatable condition must create some anxiety."15

The importance of adequate diagnosis is essential when "patients still die of tuberculosis in the era of effective anti-tuberculous therapy."16

We thank Dr J D K Burton, HM Coroner for the western district of Greater London, for permission to use these cases. We also thank Dr P Vanezis, reader in forensic medicine and head of the department of forensic medicine and toxicology at the Charing Cross and Westminster Medical School, for his help and encouragement.

1 Whittington RM. Fatal but clinically undiagnosed tuberculosis. $\mathcal{F}$ Roy Coll Gen Practitioners 1983;33:343-5.

2 Kantor HS, Poblete R, Pusateri SL. Nosocomial transmission of tuberculosis from unsuspected disease. $\mathrm{Am} \mathcal{F} \mathrm{Med}$ 1988;84:833-8.

3 Lundgren R, Norrman E, Asberg I. Tuberculous infection transmitted at autopsy. Tubercle 1987;68:147-50.

4 Anderson RE, Hill RB, Key CR. The sensitivity and specificity of clinical diagnostics during five decades. IAMA 1989;261:1610-17.

5 Katz I, Rosenthal T, Michaeli D. Undiagnosed tuberculosis in hospitalised patients. Chest 1985;87:770-4.

6 Robbins SL, Cotran RS, Kumar V. Viral, chlamydial, Rickettsial and bacterial diseases. In: Pathologic basis of disease. 3rd Edn. Philadelphia: WB Saunders, 1984:341-6, 739-42.

7 Robbins SL, Cotran RS. Viral, chlamydial, Rickettsial and bacterial diseases. In: Pathologic basis of disease. 2nd Edn. Philadelphia: WB Saunders, 1979:401-3.

8 Citron KM. Trends in tuberculosis. Postgrad Med $\mathcal{f}$ 1984;60:187-93.

9 The Medical Research Council Tuberculosis and Chest Disease Unit. The geographical distribution of tuberculosis notifications in a national survey of England \& Wales in 1983. Tubercle 1986;67:163-78.

10 Capewell S, France AJ, Anderson M, Leitch AG. The diagnosis and management of tuberculosis in common hostel dwellers. Tubercle 1986;67:125-31.

11 Ramsden SS, Baur S, El Kabir DJ. Tuberculosis among the Central London single homeless. $\mathcal{F}$ Roy Coll Phys Lond 1988;22:16-17.

12 McAdams J, Brickner P, Glicksman R, et al. Health care of homeless people. New York: Springer Publishing Co. 1985:155.

13 Ohta Y. The epidemiological study of physical morbidity in schizophrenics-2. Association between schizophrenia and incidence of tuberculosis. $f a p \quad \mathcal{f}$ Psychol Neurol 1988;42:41-7.

14 Chanarin I, Stephenson E. Vegetarian diet and cobalamin deficiency: their association with tuberculosis. $\mathcal{f}$ Clin Pathol 1988;41:759-62.

$15 \mathrm{McNicol} \mathrm{M}$. Trends in the epidemiology of tuberculosis-a physician's view. $f$ Clin Pathol 1983;36:1087-90.

16 Davis CE, Jr, Carpenter JL, McAllister K, et al. Tuberculosis. Cause of death in the antibiotic era. Chest 1985;88:726-9. 